\title{
Molecular Cloning and Tissue Distribution of Troponin C from the Japanese Pearl Oyster, Pinctada fucata
}

\author{
Daisuke Funabara*, Yoshinori Urakawa, Satoshi Kanoh \\ Graduate School of Bioresources, Mie University, Tsu, Japan \\ Email: ^funabara@bio.mie-u.ac.jp
}

How to cite this paper: Funabara, D., Urakawa, Y. and Kanoh, S. (2018) Molecular Cloning and Tissue Distribution of Troponin C from the Japanese Pearl Oyster, Pinctada fucata. American Journal of Molecular Biology, 8, 166-177.

https://doi.org/10.4236/ajmb.2018.83014

Received: May 14, 2018

Accepted: July 2, 2018

Published: July 5, 2018

Copyright $\odot 2018$ by authors and Scientific Research Publishing Inc. This work is licensed under the Creative Commons Attribution International License (CC BY 4.0).

http://creativecommons.org/licenses/by/4.0/ Open Access

\begin{abstract}
Troponin $\mathrm{C}(\mathrm{TnC})$ is one of the subunits of troponin. Troponin, which is activated by $\mathrm{Ca}^{2+}$ binding, is a thin filament-associated regulator of vertebrate striated muscle contraction. The function of $\mathrm{TnC}$ in vertebrates has been characterized in detail, but the role of $\mathrm{TnC}$ in molluscan muscles is still unclear. In this work, we investigated whether $\mathrm{TnC}$ plays a role in the catch contraction of molluscan smooth muscle in the bivalve Japanese pearl oyster Pinctada fucata. We determined the full-length primary structure of the TnC protein from the $P$. fucata adductor muscle (Pifuc-TnC), and found it is composed of 150 amino acid residues with a predicted molecular weight of 17,400. Multiple sequence alignments indicated that it had four EF-hand motifs, but only one (site IV) was predicted to have $\mathrm{Ca}^{2+}$-binding ability. This is analogous to characterized TnCs from other mollusks. Three-dimensional modeling of Pifuc-TnC using SWISS-MODEL indicated the presence of a short loop within the $\alpha$-helix connecting the site II and III EF-hand motifs. We predicted the gene structure of Pifuc-TnC using Splign alignment of our obtained cDNA and genome sequences and elucidated that Pifuc-TnC consists of five exons, with the start and stop codons located in exon 1 and exon 5 , respectively. Using quantitative real-time PCR, we determined that the Pifuc-TnC gene is predominantly expressed in adductor phasic muscle and rarely in adductor catch muscle, gill, mantle and foot. These findings suggest that $\mathrm{TnC}$ may not have a role in catch muscle contraction.
\end{abstract}

\section{Keywords}

Adductor Muscle, Catch Contraction, EF-Hand, Troponin, Troponin C

\section{Introduction}

Troponin (Tn) is the sarcomeric $\mathrm{Ca}^{2+}$-dependent regulator for striated muscle 
contraction in vertebrates. It is distributed on thin filaments and inhibits the interaction between actin and myosin. Troponin consists of three subunits: troponin $C(\operatorname{TnC})$, troponin $\mathrm{I}(\mathrm{TnI})$, and troponin $\mathrm{T}(\mathrm{Tn} T)$. The binding of $\mathrm{Ca}^{2+}$ to TnC induces a conformational change in the troponin complex structure and enables myosin to interact with actin [1]-[6].

All characterized TnCs consist of four EF-hand motifs, which possess helix-loop-helix topology and are designated as sites I-IV (from the N-terminus). Although all four vertebrate fast skeletal TnC EF-hand motifs are capable of binding $\mathrm{Ca}^{2+}$, only TnC sites II and IV are able to bind $\mathrm{Ca}^{2+}$ in arthropod and nematode striated muscles [7] [8]. In mollusks such as scallop and squid, only site IV is able to bind to $\mathrm{Ca}^{2+}$ [9] [10]. The ability of an EF-hand motif to bind $\mathrm{Ca}^{2+}$ is dependent upon its primary structure [11].

Both vertebrate and molluscan muscle contraction are regulated by intracellular $\mathrm{Ca}^{2+}$ concentrations [12]. However, in contrast to vertebrates, mollusks employ a thick filament-linked regulatory system where myosin binds $\mathrm{Ca}^{2+} \mathrm{di}-$ rectly leading to its activation and subsequent interaction with actin. Although Tn is also located in molluscan muscles, it is currently unclear whether it is involved in a similar thin filament-linked regulatory system to that in vertebrates.

Bivalve adductor muscles are composed of two muscle types: phasic and catch. The large phasic muscle is used for quick closure of shells, whereas the smaller catch muscle is involved in the sustainable closure of shells. Catch muscles can develop a long-lasting high tension state with little energy expenditure. They begin to contract following an increase in intracellular $\mathrm{Ca}^{2+}$ concentrations, which activates myosin and develops the tension. They subsequently enter the catch state once $\mathrm{Ca}^{2+}$ concentrations decrease to resting levels [12]. In the catch state, thin and thick filaments are thought to be tethered together by a complex of myosin, actin, and twitchin, a giant myosin-associated protein [13] [14] [15]. However, there are currently no data to suggest that thin filament-linked regulation is involved in catch contraction.

The genome database of the pearl oyster Pinctada fucata has been completely determined and we have already located and annotated genes encoding fundamental muscle proteins [16] [17] [18]. Recently, it has been reported that gene expression patterns differ between scallop phasic and catch muscles as revealed by proteomic and transcriptomic analyses. Troponin is expressed in phasic muscle higher than catch muscle, indicating a different regulatory system might be employed in each muscle [19]. However, there are little data available to suggest the function of all the elucidated muscle proteins in molluscan muscle contraction. Therefore, in this study, we performed a molecular characterization of Pinctada fucata troponin C (Pifuc-TnC) to investigate if it is involved in catch contraction.

\section{Materials and Methods}

\subsection{Pearl Oysters}

We obtained live specimens of the Japanese pearl oyster, Pinctada fucata that 
were cultured in Ago Bay, Mie Prefecture, Japan. The adductor muscle, gill, mantle, and foot were dissected from each oyster body, immediately frozen in liquid nitrogen, and stored at $-80^{\circ} \mathrm{C}$ until use.

\section{2. cDNA Cloning of Pinctada fucata Troponin C}

Total RNA was extracted from the phasic part of the adductor muscle using a conventional method [20]. First strand cDNA was synthesized using the 3'-Full RACE Core Set (TaKaRa-Bio, Ohtsu, Japan) using the total RNA as the template. Three 3' RACE primers were designed based on the partial sequence of $\mathrm{Pi}$ fuc-TnC: 5'-GTAGAGGACTTAAGGTGGAT-3' for the first PCR, 5'-TAAAATCGTTAGGTGATGAT-3' for the nested PCR, and 5'-TTCACCATAAAGGTCACCCT-3' for the second nested PCR [18]. PCR was carried out using SapphireAmp Fast PCR Master Mix (TaKaRa-Bio) with the forward primers detailed above and the Oligo dT-3 sites adaptor primer. PCR conditions were as follows: 30 cycles of denaturation at $98^{\circ} \mathrm{C}$ for $5 \mathrm{~s}$, annealing at $55^{\circ} \mathrm{C}$ for $5 \mathrm{~s}$, and elongation at $72^{\circ} \mathrm{C}$ for $20 \mathrm{~s}$. The amplified DNA fragment was sequenced after insertion into a pTAC-1 vector (BioDynamics Laboratory Inc., Tokyo, Japan). 5' RACE was carried out using the 5' RACE system for Rapid Amplification of cDNA Ends, version 2.0 (Invitrogen, Carlsbad, CA, USA). Three primers were designed using the sequence determined by 3' RACE: 5'-CGTCACTCCATTCTTTGAGT-3' for synthesizing cDNA, 5'-CTCATCGTCAACTTGAAGTC-3' for the first PCR, and 5'-AAACTTTTAAAAACTTTTTC-3' for the second PCR. PCR was carried out using SapphireAmp Fast PCR Master Mix with the forward primers detailed above and the primers included in the kit. PCR conditions were as follows: 30 cycles of denaturation at $98^{\circ} \mathrm{C}$ for $5 \mathrm{~s}$, annealing at $55^{\circ} \mathrm{C}$ for $5 \mathrm{~s}$, and elongation at $72^{\circ} \mathrm{C}$ for $10 \mathrm{~s}$. The amplified DNA fragment was sequenced after insertion into a pTAC-1 vector. The determined sequence has been registered in DDBJ/EMBL/GenBank (accession number LC381286).

\subsection{Comparison of the Primary Structure of Troponin C with Those of Other Species}

The primary structure of Pifuc-TnC was deduced from the nucleotide sequence determined by cDNA cloning and compared with those from mollusks using ClustalW: akazara scallop Chlamys nipponensis akazara (BAA12908), asari clam Ruditapes philippinarum (AFB83400), and squid Todarodes pacificus (Q9BLG0); arthropods: acorn barnacle Balanus nubilus (P21798), American lobster Homarus americanus (P29289), and fruit fly Drosophila melanogaster (NP_476968); nematode: Caenorhabditis elegans (BAB84566); vertebrates: chicken Gallus gallus (NP_990781), salmon Salmo salar (ACH70760), clawed frog Xenopus laevis (NP_001079408), rabbit Oryctolagus cuniculus (NP_001076114), and human Homo sapiens (NP_003270).

\subsection{Three-Dimensional (3D) Modeling of Troponin C Structures}

The 3D structure of Pifuc-TnC was predicted with SWISS-MODEL [21] using 
the PDB data of chicken TnC (PDB: 1YTZ) as a template. To compare the structures of different TnCs, American lobster TnC (NCBI sequence FJ790224) was also modeled following the same method.

\subsection{Gene Structure of $P$. fucata Troponin C}

The genome sequence including the Pifuc-TnC gene was obtained by BLAST searching the Pifuc-TnC nucleotide sequence against the $P$. fucata genome database [17]. The gene structure of the Pifuc-TnC gene was predicted by analyzing cDNA and genome sequences using the Splign alignment tool (NCBI) [22].

\subsection{Gene Expression Analysis of $P$. fucata Troponin C in Tissues}

Gene expression patterns of Pifuc-TnC in the catch and phasic muscles, gill, mantle and foot were analyzed by quantitative real-time PCR. CDNAs were synthesized using total RNA from each tissue as templates using RiverTra Ace ${ }^{\otimes} \mathrm{qPCR}$ RT Master Mix (Toyobo Co., Ltd., Osaka, Japan). Primers and a probe were designed by Universal Probe Library Assay Design Center (Roche Diagnostics, Mannheim, Germany) using the full-length nucleotide sequence determined in this study. The primers used were: 5'-TTAACAGACGAAGAACTCGATGA-3' (forward) and 5'-TGTCCCTGAGCCGTCTGT-3' (reverse). Probe \#94 (Roche Diagnostics) was used as a TaqMan probe. P. fucata $\beta$-actin (AF378128) was used as an internal standard. The primers used for $\beta$-actin were as follows: 5'TCGTTCCTCGGAATGGAA-3' (forward), 5'-TCGACATCGCATTTGAGAAT-3' (reverse). Probe \#151 (Roche Diagnostics) was used as a TaqMan probe. The PCR reaction was performed using Eagle Taq Master Mix with ROX (Roche Diagnostics).

\section{Results}

\subsection{Molecular Characteristics of $P$. fucata Troponin C}

The full-length nucleotide sequence of Pifuc-TnC was obtained through cDNA cloning and was found to contain 1775 nucleotides (nt), which includes an open reading frame of $453 \mathrm{nt}$, a $77 \mathrm{nt} 5^{\prime}$ untranslated region, and a $1245 \mathrm{nt} 3^{\prime}$ untranslated region (Figure 1). It encodes a protein of 150 amino acid residues in length with a predicted molecular weight of 17,400 (Figure 1).

The amino acid sequence of Pifuc-TnC was $68 \%$ homologous to both asari clam and squid TnCs and was $64 \%$ homologous to akazara scallop TnC. In contrast, the Pifuc-TnC amino acid sequence exhibited between 30 and $40 \%$ homology to TnC from arthropods, nematodes and vertebrates (Table 1).

Multiple sequence alignments of Pifuc-TnC with TnCs from other organisms revealed that Pifuc-TnC has four potential EF-hand motifs, termed sites I, II, III and IV. The $\mathrm{Ca}^{2+}$ binding capability of an EF-hand motif can be predicted through analysis of its amino acid sequence [11]. Site I in Pifuc-TnC is predicted to have no $\mathrm{Ca}^{2+}$ binding ability as the third residue, which is required to be aspartic acid, asparagine or serine in order to bind to $\mathrm{Ca}^{2+}$, is a lysine. In site II, 
GACACACGGATTATAGGGAAAATATAGGTGTCCAGCTTTGCTTAGATTCTTTGCTTTCGG ATTGGTTTCTCTATCGTCATGTCGGAATTTAAAGTATCGGAAAAACAATTTGCAGATGCC $\begin{array}{lllllllllllllllllll}M & S & E & F & K & V & S & E & K & Q & F & A & D & A\end{array}$

ATACGTTCAAAAACTTGTTATCTTCTTTTGAAATTTGAATGATTGCTTCCCATCATTC 780

CATTTAACACATGCGCACTAATTGCTCTAACCCCAGAATGCATTAGCTTTGCTTGCTGCT 840

TTGCACCAACTTGCTGTCTTCCCCTATCGCGCAGCTCCACAGCACTTTTTTCTTCTCTTA 900 TGCTATGTTTATATATTGTTTCAGAGTTTTtAAACTGATGTGGGTGATTAAGCGGAC 960 TAGGACGCCCAACTTGCCCGTCTTTGTGGATGTTTGACATGCCCTCCTGTGTGCTTTCAC 1020 CATAAAGGTCACCCTCCTTACCAATCTTACCCCGGAGCTGATTTTTGTATATTTTCATGT 1080 GATATAACTTATTTGTAAATATTCATTTTTTCACATGTTATCCCAACTGATATGTTTTCT 1140 TTTTACATGGAAGGCATATATAGACTGTGTTCATCGTGTTAAGTTCTGTATCTTGCCGAC 1200 ATATTGCACTATCTGCCTGTCTCTATAACATTGGCTTCACTTACTCTGAACTGTTCATGT 1260 CATCGCCAAAAAGTTTAACATTAATTCAGTATATCGCACTATGAATGTGAACTAAACTGA 1320 CAGACTGAGTCATGCTGACTTACAACATGTTATATCTATTTATATTTACATGAGCATGCC 1380 AGATATTTTGAAATGGTACTGAGAGCATATCTATATATCAATTTGATGCAGATTTCATTA 1440 CTAATTCTGTTTTGACTTTACTCTTTAACTTGCCCAGCTAATATGTGTAAATCATAGAT 1500 AAGTATTTATATATATTCTCCACTTTGTGAATCAAGGACATTATGTATGCATGTGCTGAC 1560 TCCACATCTATGCATTCTCCTTGCCATATCTAGAAAAAAATTATTGTTTTATGTATAATT 1620 GTAATGATTCTGAGAGGAAAATGATTATAATTTGTACATTTGTGAATTTGACTGTAAAGG 1680 GTGTTTTGATGCCCAGAATAAAAGATCCTGTTGCAGCAAATGTATATGAATAAAACAGAA 1740 TATTGAACTTTTCTAAAAAAAAGAAAAAAAAAAA $\quad 1775$

Figure 1. Nucleotide and deduced amino acid sequences of Pinctada fucata troponin C. The amino acid sequences of the four predicted EF-hand motifs are underlined. The EF-hand motif that is predicted to bind $\mathrm{Ca}^{2+}$ by comparing with those from other species is shaded. The numbers on the right of the sequences denote nucleotides from the 5 '-end and amino acid residues from the $\mathrm{N}$-terminus. The stop codon is indicated by an asterisk.

Table 1. Percentage identity of the elucidated Pinctada fucata troponin C amino acid sequence to troponin C proteins from other species. The predicted $\mathrm{Ca}^{2+}$ binding sites (EF-hand motifs) are also indicated.

\begin{tabular}{|c|c|c|c|}
\hline Phylum & Species & Identity (\%) & $\mathrm{Ca}^{2+}$ binding site \\
\hline \multirow{4}{*}{ Mollusca } & Pearl oyster Pinctada fucata & - & \multirow{4}{*}{ IV } \\
\hline & Akazara scallop Chlamys nipponensis akazara & 64 & \\
\hline & Asari clam Ruditapes philippinarum & 68 & \\
\hline & Squid Todarodes pacificus & 68 & \\
\hline \multirow{3}{*}{ Arthropoda } & Acorn barnacle Balanus nubilus & 35 & \multirow{4}{*}{ II, IV } \\
\hline & American lobster Homarus americanus & 32 & \\
\hline & Fruit fly Drosophila melanogaster & 39 & \\
\hline Nematoda & Nematode Caenorhabditis elegans & 38 & \\
\hline \multirow{5}{*}{ Chordata } & Chicken Gallus gallus & 30 & \multirow{5}{*}{ I, II, III, IV } \\
\hline & Salmon Salmo salar & 33 & \\
\hline & Xenopus Xenopus laevis & 34 & \\
\hline & Rabbit Oryctolagus cuniculus fast skeletal & 31 & \\
\hline & Human Homo sapiens fast skeletal & 31 & \\
\hline
\end{tabular}


glutamic acid, phenylalanine and glutamine were identified as the third, eighth and twelfth residues, respectively, and in site III, glycine, lysine and proline were identified as the third, fifth and ninth residues, respectively. Therefore, sites II and III are also predicted to be unable to bind to $\mathrm{Ca}^{2+}$. Only site IV satisfied the amino acid requirements for $\mathrm{Ca}^{2+}$ binding, which is analogous to known TnCs from other mollusks (Figure 2 and Table 1). Therefore, out of the four potential

Site I

Pearl oyster Akazara scallop Asari clam Squid Acorn barnacle American lobster Fruit fly Nematode Chicken Salmon Clawed frog Rabbit Human

Pearl oyster Akazara scallop Asari clam Squid Acorn barnacle American lobster Fruit $f l y$ Nematode chicken Salmon Clawed frog Rabbit Human

Pearl oyster Akazara scallop Asari clam Squid Acorn barnacle American lobster Fruit fly Nematode Chicken Salmon Clawed frog Rabbit Human
------MSEFKVSEK----OFADAHQTFNLFDKKGTGQVSTKELEKVFKSLALOVDDEKL -----MSDEFRATEK----QISDAKQAFCNFDKKKEGTVSCKDLGAIFKSLGLVMKDDKI ------MTDEKVTDK----QFTDAKSTFHLYVKKGSEEVATKDLDQLFKAMALHIDDEKL ------MPVVISEK----QFNDAHQAFKLHDKKDEGAVSNKELTNLFKSLALHVSDDKL ------MMDELDKD----QIAMLKKAF DGFDHEKKGAINCDVVATI LRMMGQAYNAQTL -------MDTLDED----QVQALQKAFNS FDTDDKGFITPDTVGVI LRMMGVKISDRHL -------MDN IDEDLTPEQIAVLQKAFNS FDHQKTGS I PTEMVADI LRLMGQPFDRQIL MGDVVADALEKLSAD----QIEQFRKYFNMFDKEGKGYIRATQVGQILRTMGQAFEERDL -MASMTDQQAEARAFLSEEMIAEFKAAFDMFDADGGGDISTKELGTVMRMLGQNPTKEEL ----MTDAQQEARSFLSEEMLNEFKAAFDMFDTDGGGDISTKELGQVMRMLGQNPTRQEL -MAQPTDQQQDARSFLSEEMIAEFKAAFDMFDTDGGGDISTKELGTVMRMLGQTPTKEEL ----MTDQQAEARSYLSEEMIAEFKAAFDMFDADGGGDISVKELGTVMRMLGQTPTKEEL ----MTDQQAEARSYLSEEMIAEFKAAFDMFDADGGGDISVKELGTVMRMLGQTPTKEEL Site II

Site III KEWSDELDEEATGYFTWDQFKILFERKLKT-DEDE---RELREAFRVLDKGNKGTIPVED 106 KDWSDEVDEEATGRLSCEQWLKLEEWKLKE-DLDE---RELKEAFRVLDKEKKGVIKVDV 107 KDWADEMDEDATGLITWEKEKVLEERKLKE-DEEE---KELKEAFRVLDSQKKGVIPVSD 106 QQWVDEMDEDATGVIRWEKFKILFERKVQE-DEDE---RELRSAFRVLDKNNQGVIDVED 105 KELIDEVDADGSGMLEFEEFVTLAAKFIID-DDAEAMAKELKEAFRLYDKAGKGYIPTSA 108 QEVISETDEDGSGEIEFEEFAALAAKFLSE-EDEEALKKELKEAFRIYDRGGNGYITVHT 107 DELIDEVDEDKSGRLEFEEFVQLAAKFIVE-EDDEAMQKELREAFRLYDKQGNGYIPTSC 111 KQLIKEFDADGSGEIEFEEFAAMVANFVVNNENDEGLEEELREAFRLYDKEGNGYINVSD 116 DAIIEEVDEDGSGTIDFEEFLVMMVRQMKE-DAKGKSEEELANCFRIFDKNADGFIDIEE 118 DEIIEEVDEDGSGTIDFEEFLVMMVRLLKE-DQAGKSEEELAECFRVFDKNADGYIDREE 115 DAI IEEVDEDGSGTIDFEEFLVMMVRQMKE-DAQGKSEEELAECFRIFDKNADGYIDGEE 118 DAIIEEVDEDGSGTIDFEEFLVMMVRQMKE-DAKGKSEEELAECFRIFDRNADGYIDAEE 115 DAI IEEVDEDGSGTIDFEEFLVMMVRQMKE-DAKGKSEEELAECFRIFDRNADGYIDPEE 115 Site IV

LRWILKSLGDDLTDEELDEMIAETDTDGSGTVDYEEFKTLMTSD-- 150 LRWILKSLGDELTEDEIENMIAETDTDGSGTVDYEEFKCLMMSSDA 153 LRWILKSLGDDITEEEIDDMIAETDTDGSGTVDYEEFKSLMSSE-- 150 LRWILKSLGDDLNDDE IQDMINETDTDGSGTVDYEEFSALMLG--- 148 LKDILKELDETLNAEDLDNIIGEIDTDGSGTVDFDEFMEMMTG--- 151 LKEILRELDNKLTEDNLDS I IEEVDEDGSGTIDFNEFMKMMNG--- 150 LKEILKELDDQLTEQELDIMIEEIDSDGSGTVDFDEFMEMMTGE-- 155 LRDILRALDDNVSEEELDEMIAE IDADGSGTVDFDEFMEMMSGE-- 160 LGEILRATGEHVIEEDIEDLMKDSDKNNDGRIDFDEFLKMMEGVQ- 163 FAIIIRSTGEQISEEEIDELLKDGDKNADGMLDFDEFLKMMENVQ - 160 LAEILRSSGESITDEEIEELMKDGDKNNDGKIDFDEFLKMMEGVQ- 163 LAEIFRASGEHVTDEEIESLMKDGDKNNDGRIDFDEFLKMMEGVQ- 160 LAEIFRASGEHVTDEEIESLMKDGDKNNDGRIDFDEFLKMMEGVQ- 160

Figure 2. Multiple sequence alignments of the deduced sequence of Pinctada fucata troponin C with those from various species. The putative EF-hand motifs are highlighted in yellow (predicted to bind to $\mathrm{Ca}^{2+}$ ) and gray (predicted to be unable to bind to $\mathrm{Ca}^{2+}$ ). Compared sequences were obtained from the NCBI database: akazara scallop Chlamys nipponensis akazara (BAA12908), asari clam Ruditapes philippinarum (AFB83400), squid Todarodes pacificus (Q9BLG0), acorn barnacle Balanus nubilus (P21798), American lobster Homarus americanus (P29289), fruit fly Drosophila melanogaster (NP_476968), nematode Caenorhabditis elegans (BAB84566), chicken Gallus gallus (NP_990781), salmon Salmo salar (ACH70760), clawed frog Xenopus laevis (NP_001079408), rabbit Oryctolagus cuniculus (NP_001076114), and human Homo sapiens (NP_003270). Numbers on the right represent the numbers of the amino acid residues from the N-terminus. Gaps were inserted to optimize the sequence alignments. 
$\mathrm{Ca}^{2+}$ binding sites in Pifuc-TnC, site IV is the only EF-hand motif that is predicted to bind to $\mathrm{Ca}^{2+}$. To confirm our prediction, we are planning to make a recombinant Pifuc-TnC and its variants to be subjected to $\mathrm{Ca}^{2+}$-binding assays. A 3D model of Pifuc-TnC predicted using SWISS-MODEL was very similar to TnCs from chicken fast skeletal muscle and American lobster. The only notable difference was the presence of a short loop (four amino acids) within the $\alpha$-helix connecting the site II and III EF-hand motifs (Figure 3). Similar structures were also predicted for $\mathrm{TnC}$ from other mollusks: akazara scallop and squid (data not shown). This structural divergence does suggest functional differences between molluscan and vertebrate TnCs. $\mathrm{Ca}^{2+}$ binding by vertebrate fast skeletal TnC involves all four EF-hand motifs and leads to drastic conformational changes to trigger the interaction between myosin and actin. Although it has been reported that the conformation of molluscan $\mathrm{TnC}$ does change upon $\mathrm{Ca}^{2+}$ binding, the degree of the structural change and if it consequently modifies the role of troponin in the regulation of molluscan muscle contraction remain unknown [23]. Further studies are required to unveil the role of troponin in molluscan muscle.

\subsection{Gene Structure of the P. fucata Troponin C Gene}

BLAST searching of our obtained Pifuc-TnC nucleotide sequence against the genome database of $P$. fucata yielded a single nucleotide sequence at scaffold 1306.1. In our previous study, we annotated a gene model (pfu_aug1.0_1306.1_22530) that was automatically predicted by the genome database to be TnC [18]. The gene model contained the predicted full-length amino acid sequence of $\mathrm{TnC}$, which is identical to the sequence determined in this study. We then predicted the gene structure of Pifuc-TnC using Splign alignment of the obtained cDNA and genome sequences. Pifuc-TnC consists of five exons (Figure 4), and the start and stop codons are located in exon 1 and exon 5, respectively.

\subsection{Distribution of Troponin C in $P$. fucata Tissues}

Pifuc-TnC was predominantly expressed in phasic adductor muscle, while weak expression was detected in catch adductor muscle, gill, mantle and foot (Figure 5). $\mathrm{TnC}$ is a key regulator in the fast contraction of vertebrate striated muscles (skeletal and cardiac muscles). The phasic adductor muscle is thought to control the quick closure of shells. Our findings suggest that TnC could be involved in the regulation of the phasic adductor muscle, rather than the catch adductor muscle. However, it has been reported that $\mathrm{TnC}$ was isolated from both the phasic and catch adductor muscles of the akazara scallop [24]. It is possible that the function of $\mathrm{TnC}$ is species-dependent.

\section{Discussion}

In this study, we have analyzed the molecular characteristics of Pifuc-TnC. Our findings have indicated that Pifuc-TnC has a similar structure to known molluscan TnCs, indicating that they could play analogous roles in muscle contraction. 
(a)

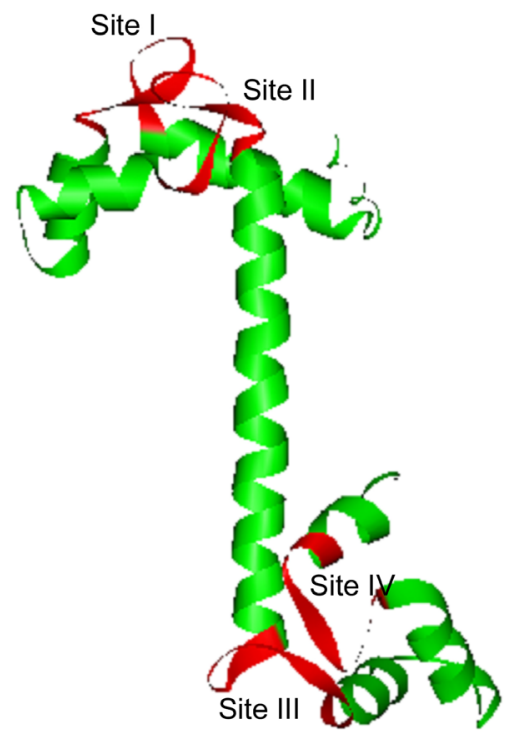

American lobster

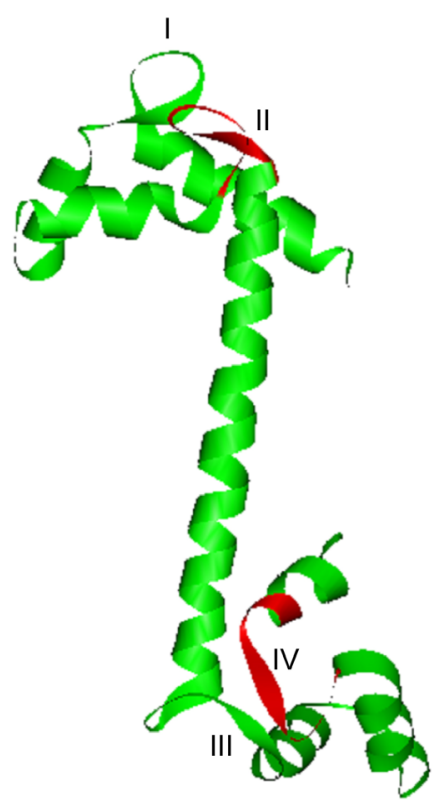

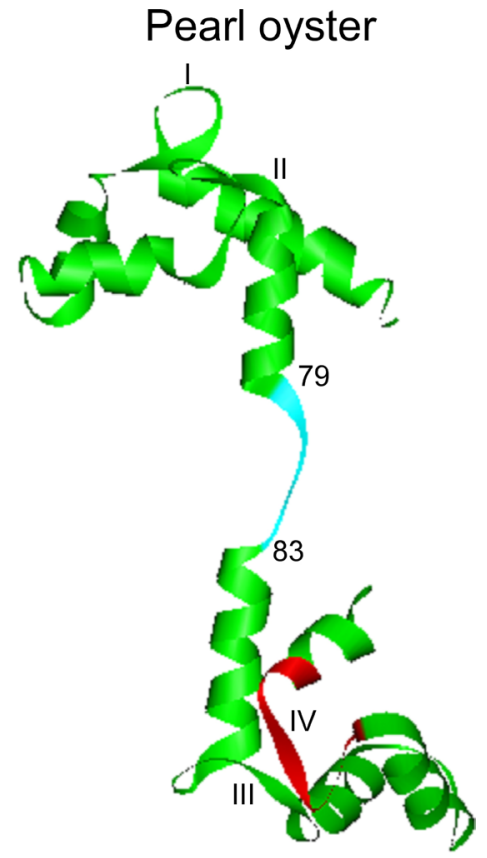

(b)

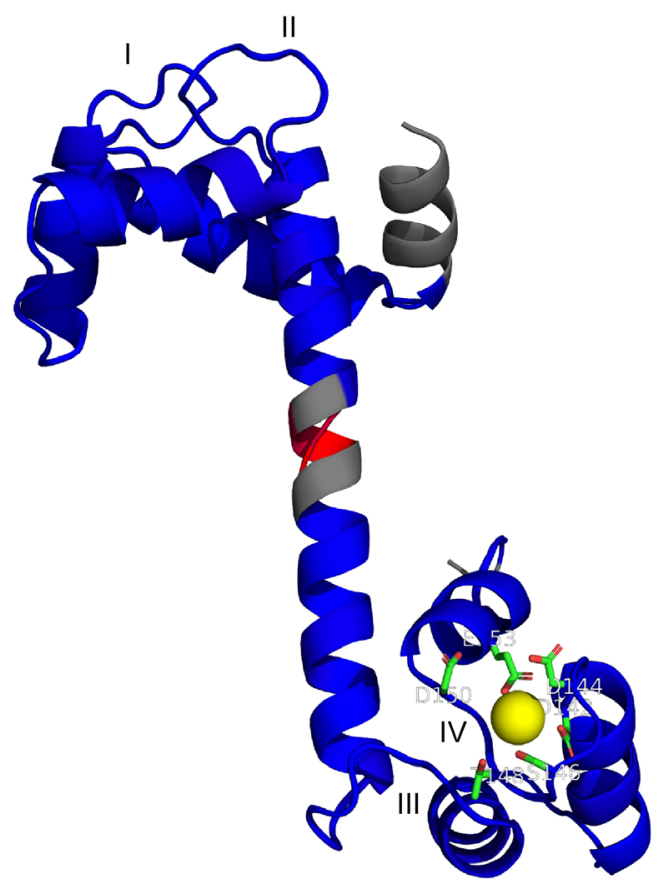

Figure 3. Three-dimensional modeling of troponin C. (a) Three-dimensional models of troponin C from chicken fast skeletal muscle, American lobster and pearl oyster. Troponin C models of American lobster and pearl oyster were predicted using the SWISS-MODEL program using the PDB data from chicken troponin C (PDB: 1YTZ) as a template. The amino acid sequence of American lobster troponin C was obtained from the NCBI database (FJ790224). EF-hand motifs predicted to bind to Ca ${ }^{2+}$ are shown in red. The region that does not form an $\alpha$-helix structure in the pearl oyster troponin C model is shown in blue. The numbers in the pearl oyster troponin $\mathrm{C}$ model represent numbers of amino acid residues from the N-terminus. (b) The superimposed image of the three-dimensional models from chicken fast skeletal and pearl oyster troponin Cs. The image is colored by RMSD. Side chains of amino acid residues considered to be involved in $\mathrm{Ca}^{2+}$ binding are represented by sticks. The $\mathrm{Ca}^{2+}$ atom is indicated in yellow. 


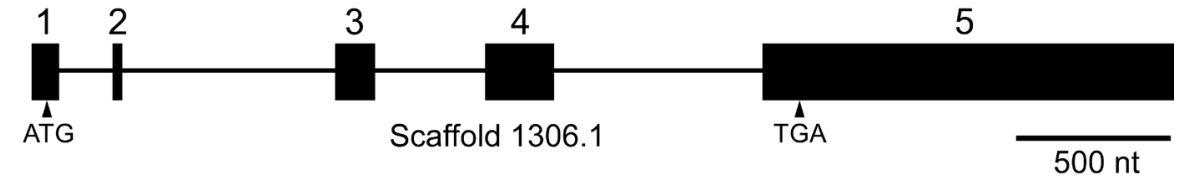

Figure 4. Gene structure of Pinctada fucata troponin C. Black boxes indicate exons, and intervening lines represent introns. The ATG start codon and TGA stop codons are indicated.

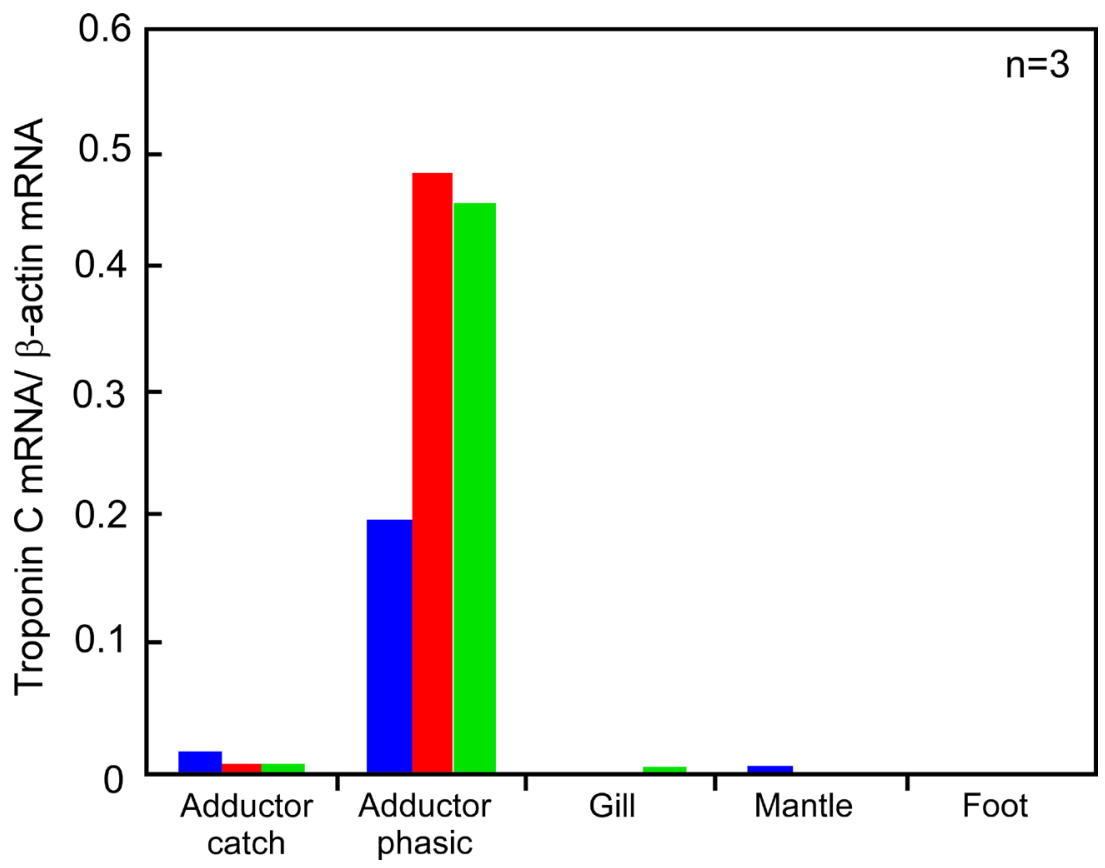

Figure 5. Gene expression patterns of troponin C in Pinctada fucata tissues. Quantitative real-time PCR analysis was performed to examine troponin C gene expression in Pinctada fucata adductor catch muscle, adductor phasic muscle, gill, mantle, and foot. The data shown are from three independent experiments. The $\mathrm{y}$-axis indicates relative troponin $\mathrm{C}$ expression levels using $\beta$-actin as an internal standard.

Pifuc-TnC and other characterized molluscan TnCs have four EF-hand motifs, but only one is predicted to bind to $\mathrm{Ca}^{2+}$. In contrast, all four vertebrate fast skeletal TnC EF-hand motifs are able to bind $\mathrm{Ca}^{2+}$. The predicted 3D models of molluscan TnCs also differ substantially from those of vertebrate fast skeletal TnCs. To date, numerous studies have accumulated a large amount of data on vertebrate TnC function. However, the observed divergences in structure and $\mathrm{Ca}^{2+}$ binding mean it is impossible to extrapolate these findings to the function of molluscan TnCs. Indeed, it has been reported that akazara scallop TnC is likely to function in a different manner to vertebrate TnCs [23] [25].

The Pifuc-TnC gene is predominantly expressed in phasic muscle and not in catch muscle, suggesting that in the pearl oyster $P$. fucata, TnC may be involved in the regulation of phasic muscle contraction. We have previously reported that isoforms of twitchin, a known regulator of catch muscle contraction, are expressed in both phasic and catch muscles, and indicated that the divergent properties of these muscle types might be attributed to the presence of different 
twitchin isoforms [26]. It is also possible that troponin is able to preclude twitchin-regulated catch contraction activity in phasic muscle.

Troponin is a complex of three subunits: TnC, together with TnI and TnT. Our previous studies have elucidated partial sequences of Pifuc-TnI and Pifuc-TnT genes in the genome database [18]. Further molecular characterization studies on Pifuc-TnI and Pifuc-TnT are required to clarify the function of troponin in Pinctada fucata.

\section{Acknowledgements}

This study was supported by JSPS KAKENHI Grant Number JP16K07872. We thank Emma Andrew, PhD, from Edanz Group (https://www.edanzediting.com/?utm_source=ack\&utm_medium=journal) for editing a draft of this manuscript.

\section{References}

[1] Leavis, P.C., Gergely, J. and Szent-Gyorgyi, A.G. (1984) Thin Filament Proteins and Thin Filament-Linked Regulation of Vertebrate Muscle Contraction. Critical Reviews in Biochemistry, 16, 235-305. https://doi.org/10.3109/10409238409108717

[2] Ohtsuki, I., Maruyama, K. and Ebashi, S. (1986) Regulatory and Cytoskeletal Proteins of Vertebrate Skeletal Muscle. Advances in Protein Chemistry, 38, 1-67. https://doi.org/10.1016/S0065-3233(08)60525-2

[3] Zot, A.S. and Potter, J.D. (1987) Structural Aspects of Troponin-Tropomyosin Regulation of Skeletal Muscle Contraction. Annual Review of Biophysics and Biophysical Chemistry, 16, 535-559. https://doi.org/10.1146/annurev.bb.16.060187.002535

[4] Grabarek, Z., Tao, T. and Gergely, J. (1992) Molecular Mechanism of Troponin-C Function. Journal of Muscle Research \& Cell Motility, 13, 383-393. https://doi.org/10.1007/BF01738034

[5] Farah, C.S. and Reinach, F.C. (1995) The Troponin Complex and Regulation of Muscle Contraction. The FASEB Journal, 9, 755-767.

https://doi.org/10.1096/fasebj.9.9.7601340

[6] Tobacman, L.S. (1996) Thin Filament-Mediated Regulation of Cardiac Contraction. Annual Review of Physiology, 58, 447-481. https://doi.org/10.1146/annurev.ph.58.030196.002311

[7] Garone, L., Theibert, J.L., Miegel, A., Maeda, Y., Murphy, C. and Collins, J.H. (1991) Lobster Troponin C: Amino Acid Sequences of Three Isoforms. Archives of Biochemistry and Biophysics, 291, 89-91. https://doi.org/10.1016/0003-9861(91)90108-U

[8] Terami, H., Williams, B.D., Kitamura, S., Sakube, Y., Matsumoto, S., Doi, S., Obinata, T. and Kagawa, H. (1999) Genomic Organization, Expression, and Analysis of the Troponin C Gene Pat-10 of Caenorhabditis elegans. The Journal of Cell Biology, 146, 193-202.

[9] Ojima, T., Tanaka, H. and Nishita, K. (1994) Cloning and Sequence of a cDNA Encoding Akazara Scallop Troponin C. Archives of Biochemistry and Biophysics, 311, 272-276. https://doi.org/10.1006/abbi.1994.1237

[10] Ojima, T., Ohta, T. and Nishita, K. (2001) Amino Acid Sequence of Squid Troponin C. Comparative Biochemistry and Physiology Part B: Biochemistry and Molecular 
Biology, 129, 787-796. https://doi.org/10.1016/S1096-4959(01)00397-9

[11] Gifford, J.L., Walsh, M.P. and Vogel, H.J. (2007) Structures and Metal-Ion-Binding Properties of the $\mathrm{Ca}^{2+}$-Binding Helix-Loop-Helix EF-Hand Motifs. Biochemical Journal, 405, 199-221. https://doi.org/10.1042/BJ20070255

[12] Funabara, D., Kanoh, S., Siegman, M.J., Butler, T.M., Hartshorne, D.J. and Watabe, S. (2005) Twitchin as A Regulator of Catch Contraction in Molluscan Smooth Muscle. Journal of Muscle Research \& Cell Motility, 26, 455-460. https://doi.org/10.1007/s10974-005-9029-2

[13] Funabara, D., Watabe, S., Mooers, S.U., Narayan, S., Dudas, C., Hartshorne, D.J., Siegman, M.J. and Butler, T.M. (2003) Twitchin from Molluscan Catch Muscle: Primary Structure and Relationship between Site-Specific Phosphorylation and Mechanical Function. The Journal of Biological Chemistry, 278, 29308-29316. https://doi.org/10.1074/jbc.M303272200

[14] Funabara, D., Hamamoto, C., Yamamoto, K., Inoue, A., Ueda, M., Osawa, R., Kanoh, S., Hartshorne, D.J., Suzuki, S. and Watabe, S. (2007) Unphosphorylated Twitchin Forms A Complex with Actin and Myosin that May Contribute to Tension Maintenance in Catch. Journal of Experimental Biology, 210, 4399-4410. https://doi.org/10.1242/jeb.008722

[15] Funabara, D., Osawa, R., Ueda, M., Kanoh, S., Hartshorne, D.J. and Watabe, S. (2009) Myosin Loop 2 Is Involved in the Formation of A Trimeric Complex of Twitchin, Actin, and Myosin. The Journal of Biological Chemistry, 284, 18015-18020. https://doi.org/10.1074/jbc.M109.016485

[16] Takeuchi, T., Kawashima, T., Koyanagi, R., Gyoja, F., Tanaka, M., Ikuta, T., Shoguchi, E., Fujiwara, M., Shinzato, C., Hisata, K., Fujie, M., Usami, T., Nagai, K., Maeyama, K., Okamoto, K., Aoki, H., Ishikawa, T., Masaoka, T., Fujiwara, A., Endo, K., Endo, H., Nagasawa, H., Kinoshita, S., Asakawa, S., Watabe, S. and Satoh, N. (2012) Draft Genome of the Pearl Oyster Pinctada fucata: A Platform for Understanding Bivalve Biology. DNA Research, 19, 117-130. https://doi.org/10.1093/dnares/dss005

[17] Takeuchi, T., Koyanagi, R., Gyoja, F., Kanda, M., Hisata, K., Fujie, M., Goto, H., Yamasaki, S., Nagai, K., Morino, Y., Miyamoto, H., Endo, K., Endo, H., Nagasawa, H., Kinoshita, S., Asakawa, S., Watabe, S., Satoh, N. and Kawashima, T. (2016) Bivalve-Specific Gene Expansion in the Pearl Oyster Genome: Implications of Adaptation to A Sessile Lifestyle. Zoological Letters, 2, 3. https://doi.org/10.1186/s40851-016-0039-2

[18] Funabara, D., Watanabe, D., Satoh, N. and Kanoh, S. (2013) Genome-Wide Survey of Genes Encoding Muscle Proteins in the Pearl Oyster, Pinctada fucata. Zoological Science, 30, 817-825. https://doi.org/10.2108/zsj.30.817

[19] Sun, X., Liu, Z., Wu, B., Zhou, L., Wang, Q., Wu, W. and Yang, A. (2018) Differences between Fast and Slow Muscles in Scallops Revealed through Proteomics and Transcriptomics. BMC Genomics, 19, 377. https://doi.org/10.1186/s12864-018-4770-2

[20] Chomczynski, P. (1993) A Reagent for the Single-Step Simultaneous Isolation of RNA, DNA and Proteins from Cell and Tissue Samples. Biotechniques, 15, 532-534, 536-537.

[21] Biasini, M., Bienert, S., Waterhouse, A., Arnold, K., Studer, G., Schmidt, T., Kiefer, F., Cassarino, T.G., Bertoni, M., Bordoli, L. and Schwede, T. (2014) SWISS-MODEL: Modelling Protein Tertiary and Quaternary Structure Using Evolutionary Information. Nucleic Acids Research, 42, W252-W258. https://doi.org/10.1093/nar/gku340 
[22] Kapustin, Y., Souvorov, A., Tatusova, T. and Lipman, D. (2008) Splign: Algorithms for Computing Spliced Alignments with Identification of Paralogs. Biology Direct, 3, 20. https://doi.org/10.1186/1745-6150-3-20

[23] Ojima, T. and Nishita, K. (1986) Isolation of Troponins from Striated and Smooth Adductor Muscles of Akazara Scallop. The Journal of Biochemistry, 100, 821-824. https://doi.org/10.1093/oxfordjournals.jbchem.a121777

[24] Ojima, T. and Nishita, K. (1992) Akazara Scallop Troponin C: $\mathrm{Ca}^{2+}$-Induced Conformational Change and Interaction with Rabbit Troponin Subunits. Archives of Biochemistry and Biophysics, 299, 344-349. https://doi.org/10.1016/0003-9861(92)90285-5

[25] Shiraishi, F., Morimoto, S., Nishita, K., Ojima, T. and Ohtsuki, I. (1999) Effects of Removal and Reconstitution of Myosin Regulatory Light Chain and Troponin $\mathrm{C}$ on the $\mathrm{Ca}^{2+}$-Sensitive ATPase Activity of Myofibrils from Scallop Striated Muscle. The Journal of Biochemistry, 126, 1020-1024.

https://doi.org/10.1093/oxfordjournals.jbchem.a022545

[26] Funabara, D., Watabe, S. and Kanoh, S. (2015) Phosphorylation Properties of Twitchin from Yesso Scallop Catch and Striated Muscles. Fisheries Science, 81, 541-550. https://doi.org/10.1007/s12562-015-0866-7 